\title{
Entre a legislação e a realidade das salas de aula: uma análise das políticas educacionais voltadas ao livro didático durante a Ditadura Civil-militar no Brasil a partir do relato de educadores ${ }^{1}$
}

Clarissa de Lourdes Sommer Alves*

Resumo: Neste artigo analiso a relação entre as políticas educacionais elaboradas pela Ditadura civil-militar para o livro didático entre 1964 e 1974 e a realidade da utilização destes materiais nas salas de aula naqueles anos, compreendendo este período como de institucionalização e apogeu do regime ditatorial no país. Para isto, investigo tanto a legislação e publicaçóes oficiais quanto entrevistas feitas com educadores que lecionaram na época. Através destas entrevistas aprofundo a análise da relação entre os educadores e os livros didáticos enquanto instrumentos de ensino-aprendizagem, buscando saber se existia um real acesso a tais materiais; como ele se dava; e se houve mudanças ao longo destes anos na área, refletindo, assim, sobre como as políticas educacionais elaboradas pelo Estado para este setor se relacionavam com o dia a dia das salas de aula e com os objetivos estratégicos do Estado naquele momento histórico.

Palavras-chave: História, Ditadura civil-militar, Política educacional, Livro didático.

Artigo elaborado a partir do trabalho de conclusão de curso intitulado $A$ Ditadura Civil-militar no Brasil e as políticas educacionais para o livro didático (1964-1974), produzido para obtenção do referido título de graduação, em dez/2009, sob orientação do Prof. Dr. Enrique Serra Padros.

* Licenciada em História pela UFRGS. Aluna do Curso de Bacharelado em História da UFRGS. E-mail: clarissaalves@yahoo.com.br. 


\begin{abstract}
This article analyzes the relationship between the educational policies developed by the Brazilian civil-military Dictatorship for the textbooks between 1964 and 1974 and the uses of these kind of materials in classrooms in those years, understanding this period as the institutionalization and the apex of the dictatorial regime in the country. For that, I investigate both the legislation and official publications as textbooks published in the period and interviews with educators who taught at the time. Through these interviews I deepen the analysis of the relationship between the textbooks as instruments for teaching and learning, investigating if there was a real access to such materials; how it was made; and if there were changes over the years in the area, reflecting therefore about how the educational policies developed by the State for this sector were related to the daily life of classrooms and with the strategic goals of the State at that historic moment.
\end{abstract}

Keywords: History, Civil-military Dictatorship, Educational policies, Textbooks.

A partir de minhas experiências com o ensino, seja como discente na educação básica e nas disciplinas voltadas à licenciatura no ensino superior, seja como educadora em estágios e trabalhos voluntários desenvolvidos ao longo do curso de História, pude vislumbrar a forte presença que os livros didáticos marcam nas salas de aula. Discute-se muito a respeito deste instrumento de ensino e aprendizagem, ora sobre a necessidade de serem ou não adotados pelos educadores; ora sobre a legitimidade e a autonomia dos professores no processo de construção e escolha destes materiais; ou sobre a sua qualidade técnica e científica; sobre a interferência ou não interferência do Estado neste setor, etc. Mas, para além de qualquer discussão que possa ser relembrada e mencionada aqui, algo é passível de afirmação segura: hoje o livro didático é, sim, uma ferramenta muito utilizada na educação formal básica, tanto na rede privada quanto na rede pública, já que o Estado desenvolve uma série de programas para promover a distribuição dos mesmos. Em muitos casos o livro chega a ser o único material de 
apoio pedagógico utilizado pelos professores, tornando-se o "guia" adotado por eles para embasar suas aulas, buscar proposiçôes de atividades, trabalhos e avaliações, como assegura Gatti Junior:

Pode-se afirmar que os livros didáticos são, incontestavelmente, instrumentos privilegiados no cenário educacional, pois são eles que, verdadeiramente, estabelecem grande parte das condições materiais para o ensino e a aprendizagem nas salas de aula [...] Ao fornecer estas condições, eles acabam sendo fiéis depositários dos saberes provenientes das diferentes disciplinas escolares. Os livros didáticos, nesse sentido, rivalizaram quando não, em certo sentido, substituíram os professores no decorres destes anos, passando a serem os portadores dos conteúdos explícitos a serem transmitidos aos alunos e, também [...] tornando-se os organizadores das atividades didático-pedagógicas exercidas pelos docentes para viabilizar os processos de ensino e de aprendizagem (GATTI Jr., 2004, p. 27).

Conforme dados divulgados pela Fundação Nacional de Desenvolvimento da Educação (FNDE), somente entre os anos de 2005 e 2009 o governo federal gastou mais de 855 milhões de reais em livros didáticos para o Ensino Médio, e mais de 1 bilhão e meio de reais para o Ensino Fundamental, totalizando cerca de 560 milhões de exemplares de livros comprados para distribuição entre os alunos, deixando de fora deste cálculo tanto a compra de dicionários quanto de livros para as bibliotecas escolares. Nesta perspectiva, são necessários estudos que busquem não apenas discutir o papel do livro didático enquanto instrumento pedagógico, mas também conhecer e compreender o processo de sua constituição como um instrumento tão central ao ensino no Brasil, assim como seu real impacto nas salas de aula ao longo deste processo.

Percebendo que os governos que estiveram à frente do Estado brasileiro durante a ditadura civil-militar passaram a dedicar atenção especial ao livro didático, e que o período entre 1964 e 1974 é marcante no que concerne a consolidação de uma política estatal para este setor, neste artigo exploro tais questões buscando demonstrar de que maneira se deu a transposição das políticas educacionais elaboradas pelo Estado no nível superestrutural para 
a realidade objetiva, ou seja, para a realidade das escolas brasileiras. Afinal, bem sabemos que nem sempre as políticas formuladas e organizadas são plenamente implementadas, podendo deixar de cumprir a função para o qual foram elaboradas e perdendo a capacidade de interferência efetiva nas estruturas sociais.

Considerando que a educação escolar exerce um papel fundamental na concretização dos projetos políticos e sociais mais abrangentes dos grupos dirigentes, e considerando política educacional como "o conjunto de medidas tomadas (ou apenas formuladas) pela sociedade política que dizem respeito ao aparelho de ensino visando à reprodução da força de trabalho e dos intelectuais (em sentido amplo), à regulação dos requisitos educacionais e à inculcação da ideologia dominante" (GERMANO, 1993, p. 32), visualiza-se a importância e a atualidade das discussões a respeito das políticas voltadas ao livro didático.

Parto aqui do pressuposto teórico de que a educação formal, como instituição regulada pelo Estado, é reprodutora da ordem social vigente - no caso, a ordem capitalista-e desta maneira responde aos interesses da classe dominante, que utiliza a estrutura do ensino formal como uma das formas de disseminar o conhecimento por ela balizado, disseminando sua ideologia como a hegemônica, garantindo a hegemonia de classe. É essencial esclarecer que "isso não ocorre sem contradições, sem problemas, sem limites impostos pela realidade e pela correlação de forças sociais que se defrontam em defesa dos seus interesses, numa palavra, sem luta" (GERMANO, 1993, p. 104) e, acrescentar-se-ia ainda, sem contradição dialética entre os sujeitos que compõe a base real do Estado.

Compreendendo o Estado com seu recorte de classes e seu papel de mantenedor da ordem vigente, torna-se fundamental pensar na utilização da educação formal oferecida por ele como forma de garantir o status quo e coesionar as classes subalternas.

A organização escolar, ao lado da Igreja e das organizações de imprensa, aparece como um dos principais aparelhos através do qual a classe dominante garante sua estrutura ideológica, "entendendo-se por este termo a organização material destinada 
a manter, defender e desenvolver a 'frente teórica" (PORTELLI, 1977, p. 27) de determinado grupo ou classe social. Neste contexto, "a imprensa e a edição, assim como a organização escolar, assumem papel essencial, pois são as únicas a abranger o domínio da ideologia (livros e revistas científicas, políticas, literárias...) e seus degraus (livros e diários para a 'elite', para vulgarização popular...)" (PORTELLI, 1977, p. 28), ou seja, são meios através dos quais a classe dominante pode disseminar as ideias que defende para os diversos grupos sociais, com teores distintos de acordo com o 'público-alvo', porém perseguindo-se o mesmo objetivo, de manutenção da posição hegemônica.

Desta maneira, é consequente pensar nas políticas educacionais para o livro didático como expressões dos interesses da classe dominante representada pelo Estado. O livro didático, quando pensado para ser oferecido a amplas camadas da sociedade, pode ser um eficiente instrumento de transmissão ideológica já que, além de ser por si só um mecanismo de difusão de ideias, ainda teria sua capacidade potencializada ao ser analisado dentro do ambiente escolar, também direcionado de maneira organizada a servir como aparelho ideológico do Estado.

Para manter a hegemonia, ou para aumentar a influência de sua ideologia assegurando adesão e consentimento das massas, a classe dominante utiliza-se tanto dos aparelhos repressivos de Estado, quanto dos seus aparelhos ideológicos. ${ }^{2}$ Além disto, para assegurar a expansão da acumulação de capital e o avanço das forças

2 Segundo Althusser, "Para avançar na teoria do Estado, é indispensável ter em conta, não só a distinção entre poder de Estado e aparelho de Estado, mas também outra realidade que se situa manifestamente do lado do aparelho (repressivo) de Estado, mas não se confunde com ele. Designaremos esta realidade pelo seu conceito: os aparelhos ideológicos de Estado. Que são os aparelhos ideológicos do Estado (AIE)? Não se confundem com o aparelho (repressivo) de Estado. Lembremos que na teoria marxista, o Aparelho de Estado (AE) compreende: o Governo, a Administração, o Exército, a Polícia, os Tribunais, as Prisões, etc. [...] Designaremos por Aparelhos Ideológicos de Estado certo número de realidades que se apresentam ao observador imediato sob a forma de instituiçôes distintas e especializadas. Propomos uma lista empírica destas realidades [...]: o AIE religioso (o sistema das diferentes igrejas), o AIE escolar (o sistema das diferentes escolas públicas e particulares), o AIE familiar, o AIE jurídico" (ALTHUSSER, 1980, p. 42). 
produtivas é necessário ao Estado, representante do grupo dominante, reproduzir a qualificação da força de trabalho, que:

[...] tende (trata-se de uma lei tendencial) a ser assegurada não em 'cima das coisas' (aprendizagem na própria produção), mas, e cada vez mais, fora da produção: através do sistema escolar capitalista e outras instâncias e instituições. Ora, o que se aprende na Escola? Vai-se mais ou menos longe nos estudos, mas de qualquer maneira, aprende-se a ler, a escrever, a contar, - portanto algumas técnicas, e ainda muito mais coisas, inclusive elementos (que podem ser rudimentares ou pelo contrário aprofundados) de 'cultura científica' ou 'literária' diretamente utilizáveis nos diferentes lugares da produção [...] Aprende-se portanto 'saberes práticos'. Mas, por outro lado, e ao mesmo tempo, ensina estas técnicas e estes conhecimentos, a Escola ensina também as 'regras' dos bons costumes, isto é, o comportamento que todo o agente da divisão do trabalho deve observar, segundo o lugar que está destinado a ocupar: regras da moral, da consciência cívica e profissional, o que significa exatamente regras de respeito pela divisão social-técnica do trabalho, pelas regras da ordem estabelecida pela dominação de classe. (ALTHUSSER, 1980, p. 20-21).

Demonstra-se assim a importância do ambiente escolar e, por sua vez, das políticas educacionais elaboradas pelo Estado, como forma de coesão social, de reprodução das relações de pro-dução e também como meio de proporcionar tanto os saberes técnicos e práticos como os saberes morais capazes de levar cada indivíduo a contribuir com a acumulação e o desenvolvimento capitalista. Não é a toa que a organização e a reformulação da educação tenha se tornado tão central ao Brasil da década de 1960, em pleno desenvolvimento industrial impulsionado, principalmente, pela chegada de multinacionais e de novas tecnologias, que por sua vez exigiam um novo padrão de mão-de-obra. Estes trabalhadores deveriam ser formados, sobretudo, pela educação formal regulada pelo Estado.

O período que se estende entre 1964 e 1974, dez primeiros anos de ditadura civil-militar no Brasil, "se caracteriza não somente como uma época de consolidação e apogeu do autoritarismo, mas também [pela] realização de reformas institucionais, inclusive no campo da educação" (GERMANO, 1993, p. 101). É também neste 
momento que o Estado voltou-se a regular, através de legislação específica, a produção, compra, distribuição e financiamento dos materiais didáticos que seriam utilizados nas escolas do país.

$\mathrm{O}$ interesse da ditadura civil-militar em aumentar o acesso da população ao ensino básico, primeiro para garantir uma base de conhecimento comum capaz de homogeneizá-la, e em seguida para proporcionar subsídios à qualificação profissional tecnicista, voltada aos interesses do mercado capitalista, fez com que houvesse uma real expansão do acesso ao ensino, criando um inchamento do sistema escolar. Não é possível falar em uma democratização do ensino, mas em uma massificação do acesso, já que a simples matrícula não significa que todos terão um ensino de qualidade. Assim,

[...] a necessidade de abrigar grandes contingentes populacionais na escola, sem o devido investimento do Estado, acarretou uma situação quase trágica, em que à ausência de professores qualificados somaram-se o ingresso de alunos sem condiçóes financeiras e culturais satisfatórias e a inadequação dos espaços escolares, sem bibliotecas, etc. Nesta situação, o livro didático apareceu como o caminho que poderia assegurar a qualidade da Educação recebida por todos que estivessem na escola (GATTI Jr., 2004, p. 17).

Assim, o livro transforma-se em um material de importância fundamental em sala de aula. Também neste período ele sofreu inúmeras modificações, tanto em suas orientações teóricas quanto em seus aspectos didáticos, pedagógicos e estéticos, deixando de ser manuais pouco atrativos do ponto de vista estético e carregados de informações, para transformarem-se em livros cheios de gravuras em cores, com o conteúdo textual mais reduzido e até mesmo simplificado.

Além disso, é importante observar a relação entre o Estado e as editoras que se voltaram ao mercado do livro didático. A adoção de uma coleção de livros de determinada editora pelas escolas, tanto públicas quanto privadas, significava grande lucratividade. Prova disto é que "os investimentos governamentais nesta área cresceram vertiginosamente no decorrer do período compreendido entre as décadas de 1970 e 1990, ajudando a alavancar o setor editorial nacional” (GATTI Jr., 2004, p. 25). 
Visualizando o crescimento do alcance e do peso que o livro didático passou a ter no ensino escolar, torna-se evidente a importância de analisar as políticas educacionais voltadas a ele e a necessidade de esclarecer melhor o quanto o crescimento nos investimentos significou um crescimento real do alcance a estes materiais e ao conhecimento transmitido por eles.

\section{A legislação sobre o livro didático}

As primeiras formulações legais em relação ao livro didático são bem anteriores ao período em questão. $\mathrm{O}$ primeiro ato oficial relacionado a este tema foi a criação do Instituto Nacional do Livro (INL), através do Decreto-Lei no .93 , de 21 de dezembro 1937, por iniciativa do ministro Gustavo Capanema. As competências do INL deveriam ser: organizar e publicar a Enciclopédia Brasileira e o Dicionário de Língua Nacional; editar obras raras ou preciosas que fossem de grande interesse para a cultura nacional; promover medidas que ajudassem a melhorar e baratear o custo de edição e importação de livros; e incentivar a organização e auxiliar a manutenção de bibliotecas públicas no país. O decreto determinava que as publicações do INL seriam vendidas a preço de custo e doadas às bibliotecas públicas, mas não há menções específicas à produção ou incentivo à edição de livros didáticos.

No ano seguinte, o Decreto-Lei n ${ }^{\circ}$. 1.006, de 30 de dezembro de 1938, estabeleceu a primeira normatização para a produção, importação e utilização do livro didático, definindo que seriam considerados livros didáticos os compêndios e os livros de leitura de classe. O Capítulo I, Art. $2^{\circ} . \$ 1^{\circ}$ e $2^{\circ}$ assim determinam: "Compêndios são os livros que exponham, total ou parcialmente, a matéria das disciplinas constantes dos programas escolares. Livros de leitura de classe são os livros usados para leitura dos alunos em aula”. Este decreto-lei tornou livre a produção e a importação de livros didáticos no país, mas determinou que só pudessem ser adotados, em toda a rede de ensino, aqueles livros que fossem 
analisados e aprovados pela Comissão Nacional do Livro Didático (CNLD), vinculada ao Ministério da Educação e instituída em caráter permanente através do Capítulo II do mesmo Decreto.

A CNLD seria composta por sete membros nomeados pelo presidente e a ela caberia examinar cada livro didático que se pretendia publicar. Ao final do processo de análise deveria proferir julgamento favorável ou contrário à autorização de seu uso, apontando os motivos precisos da decisão. Eram os próprios autores ou editores que deveriam enviar à Comissão todo o material produzido, incluindo imagens, mapas, gráficos, etc., solicitando a averiguação. Em caso de parecer negativo poderiam reformular os materiais de acordo com os apontamentos feitos pela CNLD e solicitar nova avaliação.

O Decreto-Lei 1.006/38 ainda previa que caberia à CNLD denunciar ao MEC qualquer caso de descumprimento da lei, e ao MEC caberia a apreensão das edições denunciadas. Além da apreensão das obras, eram previstas penalidades como multas e prisão para aqueles que burlassem a lei. Após avaliação de todos os livros, a cada ano seria publicada lista oficial com os títulos registrados e liberados para utilização.

O Decreto-Lei no 6.339, de 11 de março de 1944, aumenta o número de membros da CNLD e determina que a publicação oficial de livros didáticos para uso em estabelecimentos de ensino passaria a ser responsabilidade do INL. O aumento do número de membros na Comissão evidencia o volume de trabalho da mesma. Ainda que o Estado tenha demonstrado preocupação com a questão, na prática, a aplicação da legislação inviabilizou-se. Em 1941, após manifestações da editoras, que eram prejudicadas pela lentidão com que a CNLD avaliava os livros, essa "reconhece ser totalmente impossível terminar em 1941 o exame dos 1.937 livros que lhes foram submetidos, ficando, portanto, prejudicada a publicação da lista dos livros em janeiro de 1942" (OLIVEIRA et al, 1984, p. 42).

Com o fim do Estado Novo, no governo interino de José Linhares, é assinado o Decreto-Lei no 8.460, de 26 de dezembro 
de 1945, que "consolida a legislação sobre as condições de produção, importação e utilização do livro didático”. Em um processo de reorganização das bases legais do país, registrando a passagem de um governo autoritário para um democrático, este Decreto parece ter servido para legitimar a política governamental para o livro didático no novo contexto, mas não refletiu em nada tal processo, já que preservou quase que integralmente a regulamentação anterior. Por isso acabou sofrendo questionamentos, inclusive judiciais "a respeito da legalidade ou não da Comissão Nacional do Livro Didático [que violaria] preceito constitucional, inviolável, como o da liberdade profissional" (OLIVEIRA et al, 1984, p. 44) ao restringir a liberdade de autores e editores. Criada durante a vigência de um regime autoritário e centralizador, esta legislação acabou por refletir os problemas gerados por decisões verticais e burocráticas.

Já “em 1952 Anísio Teixeira, então Diretor do Instituto Nacional de Estudos Pedagógicos (INEP), criou a Campanha do Livro Didático e Manuais de Ensino (CALDEME) [que deveria] elaborar livros didáticos, guias e manuais de ensino para professores e diretores das escolas" (CURY, 2009, p. 123), buscando ajudar a suprir as necessidades didáticas das escolas e remediar as deficiências de formação dos professores. Em 1956 a CALDEME foi transformada em Campanha Nacional do Material de Ensino (CNME) a partir do Decreto-Lei ${ }^{\circ}$. 38.556, de 12 de janeiro de 1956. À CNME caberia "estudar e promover medidas referentes à produção e à distribuição de material didático, com a finalidade de contribuir para a melhoria de sua qualidade e difusão do seu emprego bem como para a sua progressiva padronização”. Os materiais produzidos a partir desta Campanha não seriam distribuídos gratuitamente, mas sim vendidos a preço de custo. Através do Decreto n ${ }^{\circ} 50.489$, de 25 de abril de 1961, que "dispõe sobre o financiamento e a redução dos custos de obras didáticas e dá outras providências”, o governo Jânio Quadros estabelece a possibilidade de financiamento da produção de livros didáticos via Banco do Brasil, desde que 
[...] as obras atendessem às exigências mínimas, tais como preço de venda estabelecido pelo Banco do Brasil; parecer favorável sobre a obra emitido por comissão de três professores de notória competência, indicados pelo MEC; tiragem mínima que garantisse significativa redução do custo de produção e publicação (OLIVEIRA et al, 1984, p. 50).

Já no governo João Goulart, entra em vigor o Decreto $\mathrm{n}^{\mathrm{o}} 53.583$, de 21 de fevereiro de 1964, que viria no intuito de tentar solucionar os impasses que tanto prejudicavam a aplicação de uma política bem sucedida para o livro didático. $\mathrm{O}$ Art. $1^{\mathrm{O}}$ dava ao MEC autorização para "editar livros didáticos de todos os níveis e graus de ensino, para distribuição gratuita e venda a preço de custo em todo o País”, além de definir, em parágrafo único, que a distribuição gratuita seria feita a estudantes carentes de recursos e às bibliotecas escolares. Os livros seriam escolhidos para edição por comissão especial designada pelo MEC e deveriam ser obrigatoriamente aceitos por todas as escolas, permitindo que os alunos fizessem suas tarefas com base neste material, sem excluir a possibilidade de cada unidade de ensino adotar também outros títulos.

Esta medida não gerava a tão temida estatização da produção de livros didáticos, mas garantia aos alunos o acesso a material gratuito, "o que facilitaria a ampliação da educação popular" (OLIVEIRA et al, 1984, p. 51).

Ainda que esta medida se apresentasse como capaz de trazer desdobramentos favoráveis, apenas quatorze dias após o golpe, ainda no governo interino de Ranieri Mazzilli, o Decreto $\mathrm{n}^{\mathrm{O}} 53.887$, de 14 de abril de 1964 , revoga o 53.583 com a justificativa de que tal decreto feria a liberdade do ensino ao tornar obrigatória a adoção dos títulos publicados pelo MEC. A partir de então a política do livro didático seguiria a cargo da CNME, como vinha sendo feito. A verdade é que os interesses das classes populares e as políticas voltadas a elas ficaram em segundo plano para a ditadura civil-militar, além do que, as políticas para o livro didático, tomadas a partir de então, não tiveram como prioridade o diálogo ou parceria com pais, educadores ou educandos, mas 
sim com as empresas que concorriam no mercado editorial e que muito cresceram ao longo da ditadura.

O ano de 1966 foi decisivo para a implantação de uma política efetiva para o livro didático, que estaria marcadamente ligada às políticas gerais da ditadura civil-militar, principalmente no que concerne ao modelo de desenvolvimento econômico adotado.

O Decreto $\mathrm{n}^{\mathrm{O}} 58.653$, de 16 de junho de 1966, criou o Conselho do Livro Técnico e Didático (COLTED), "com a atribuição de gerir e aplicar recursos destinados ao financiamento e à realização de programas e projetos de expansão do livro escolar e do livro técnico, em colaboração com a Aliança para o Progresso". Os recursos que alimentariam os projetos viriam de créditos concedidos pela União ou suprimentos oriundos de outros poderes públicos, mas principalmente de verbas capitadas pela Aliança para o Progresso através de doações e empréstimos da Agência Norte Americana para o Desenvolvimento Internacional (USAID) e de outros órgãos internacionais.

Menos de quatro meses depois, o Decreto $\mathrm{n}^{\circ}$ 59.355, de 04 de outubro de 1966, revogou o anterior, instituindo a Comissão do Livro Técnico e Didático (também COLTED). Ampliando os aspectos abordados, o novo Decreto deu um caráter mais político à Comissão. Agora suas atribuições seriam "incentivar, orientar, coordenar e executar as atividades do Ministério da Educação e Cultura relacionadas com a produção, a edição, o aprimoramento e a distribuição de livros técnicos e de livros didáticos", deixando de apresentar-se apenas como um órgão gestor de recursos. A análise das considerações feitas no preâmbulo do Decreto nos ajuda a elucidar o marco político-ideológico que o ampara:

a) CONSIDERANDO que a produção e a distribuição do Livro Técnico e do Livro Didático interessam sobremodo, aos poderes públicos, pela importância de sua influência na política de educação e de desenvolvimento econômico e social do País; b) CONSIDERANDO que, na defesa desse interesse, deve o Estado manter-se numa atitude ao mesmo tempo atuante e vigilante, cabendo-lhe participar diretamente, quando necessário, da produção e distribuição de livros dessa natureza; c) CONSIDERANDO, entretanto, que nesse, como em vários outros 
setores da produção intelectual, seria contraproducente a intervenção do Estado que asfixiasse a iniciativa privada, cumprindo antes aos poderes públicos orientar e incentivar a livre concorrência, visando a intensificar a produção e a melhorar a qualidade do livro técnico e do livro didático, diminuir-lhes os preços de custo e de venda, assim como assegurar-lhes pronta distribuição [...] (Preâmbulo do Decreto no 59.355).

Aqui o Estado assume o papel preponderante que os livros possuíam para o desenvolvimento econômico e a estabilidade política do país, fazendo a defesa da livre concorrência nos marcos de sua política econômica geral. A defesa de que o Estado não asfixiasse a iniciativa privada em nada tem a ver com a garantia da liberdade de expressão de ideias para autores e editores, ou da possibilidade de produzirem-se livros a partir de referenciais teóricos plurais. O próprio sistema de organização e funcionamento da COLTED fazia com que o Estado tivesse controle efetivo sobre aquilo que seria publicado. Cabia à Direção Executiva da COLTED

[...] a responsabilidade de coordenação de todos os trabalhos relacionados com a produção e a aquisição do material didático. $\mathrm{O}$ diretorexecutivo encaminharia aos órgãos próprios do MEC, responsáveis pela seleção, as listas de livros técnicos e didáticos já publicados ou em fase de produção, já preparadas por entidades especializadas. Deveria ainda receber dos órgãos próprios do MEC as solicitações para a publicação de livros novos e providenciar a seleção de editoras que deveriam lançá-los ou, quando necessário, dos autores que deveriam escrevê-los. Os títulos aprovados seriam adquiridos pela COLTED para distribuição às bibliotecas, de, no mínimo, um exemplar para cada unidade (OLIVEIRA et al, 1984, p. 54).

Assim, a retribuiçãofinanceira recebida pelas editoras escolhidas para participar do programa servia como instrumento eficaz de controle. Aqueles dispostos a encarar o mercado editorial de livros didáticos fariam todos os esforços para adequarem-se aos interesses do Estado, mesmo que isso significasse a necessidade de readequar toda a linha produtiva.

Entre todos os acordos assinados entre o MEC e a USAID, um deles diz respeito especialmente à área de produção de livros técnicos e didáticos: o Acordo MEC-SNEL-USAID de Cooperação 
para Publicações Técnicas, Científicas e Educacionais, assinado em 06 de janeiro de 1967. Romanelli aponta que,

\begin{abstract}
por esse acordo, seriam colocados, no prazo de 3 anos, a contar de 1967, 51 milhôes de livros nas escolas. Ao MEC e o SNEL incumbiriam apenas responsabilidades de execução, mas, aos técnicos da USAID, todo o controle, desde os detalhes técnicos de fabricação do livro até os detalhes de maior importância como: elaboração, ilustração, editoração e distribuição de livros, além da orientação das editoras brasileiras no processo de compra de direitos autorais de editores não-brasileiros, vale dizer, americanos (ROMANELLI, 1985, p. 213).
\end{abstract}

A disponibilização de recursos, por parte dos Estados Unidos, para o desenvolvimento da educação em países como o Brasil fazia parte de uma política ampla de alianças no contexto da Guerra Fria, e todo o controle da aplicação da política do livro didático por parte dos técnicos norte-americanos serviria para garantir a propagação dos ideais anticomunistas.

A alta quantidade de recursos disponíveis através da COLTED, a centralização e burocratização do processo, e a corrida para ganhar concorrências, muitas vezes através da barganha e da corrupção, acabou gerando o chamado 'escândalo da COLTED. Em 1971 foi aberta uma Comissão de Inquérito para apurar as denúncias, e o Decreto $\mathrm{n}^{\circ}$ 68.728, de junho de 1971 revogou aquele que havia criado a COLTED. A partir de então o INL, criado em 1938, assumiu o papel de dirigir a política do livro didático, assumindo o acervo, o pessoal e os recursos anteriormente subordinados à COLTED. O INL deveria "autorizar a celebração de contratos, convênios e ajustes com entidades públicas e particulares e com autores, tradutores e editores, gráficos, distribuidores e livreiros" (OLIVEIRA et al, 1984, p. 57).

O fim da COLTED significava também o fim dos recursos norte-americanos direcionados especialmente aos programas de livros didáticos, trazendo a necessidade de repensar formas de financiamento. Assim, o INL passou a desenvolver um projeto de coedição de livros, em parceria com diversas editoras. Além disso, como alternativa para suprir a demanda de recursos, passou-se a 
cobrar contribuições dos estados para o Fundo do Livro Didático. A partir do Programa Nacional do Livro Didático surgiram diversos programas que pretendiam baratear o custo dos livros utilizados em todos os níveis de ensino. Surgiram assim, diversos programas: Programa do Livro Didático - Ensino Fundamental (PLIDEF); Ensino Médio (PLIDEM); Ensino superior (PLIDES); Ensino Supletivo (PLIDSU); e Ensino de Computação (PLIDECOM). O INL seguiu sendo responsável pelo Programa Nacional do Livro Didático até o ano de 1976, quando esta atribuição passou a ser da Fundação Nacional de Material Escolar, que já vinha desenvolvendo programas de distribuição de material escolar (como cadernos, lápis, borrachas e mapas) desde a sua criação, em 1967.

A partir da análise feita até aqui, fica evidente o quanto o Estado passou a envolver-se cada vez mais na questão do livro didático, seja através de políticas dependentes do capital estrangeiro, como no caso dos livros publicados e distribuídos pela COLTED com verbas norte-americanas, seja através de programas de coedição, como os desenvolvidos pelo INL.

Se em 1964 as medidas para dotar as escolas de livros didáticos eram escassas, nos três anos após a assinatura do Acordo MEC-SNEL-USAID foram distribuídos pelo Estado cerca de 51 milhões de livros comprados de diversas editoras. Já no período entre 1971 e 1973 "o Instituto Nacional do Livro publicou, em regime de coedição com empresas privadas, 38 milhões de exemplares representando cerca de $15 \%$ da produção total de livros" (OLIVEIRA et al, 1984, p. 83). Entre os anos de 1964 e 1974 é inegável o papel assumido pelo Estado na constituição de um mercado altamente lucrativo, que continuará a crescer após este período. O livro didático transformou-se, "nas condições brasileiras de produção, o grande negócio das editoras e livrarias” (FREITAG et al, 1987, p. 47). 


\section{O livro didático e o educador durante a ditadura civil-militar no Brasil: reflexões a partir de relatos}

Buscando formas de encontrar informações consistentes que pudessem me levar a conhecer o alcance real das políticas educacionais para os livros didáticos nas salas de aula durante o período em análise, nenhuma fonte pareceu mais apropriada do que aquelas que podem ser produzidas a partir dos próprios protagonistas desta história. Para isso, recorri à história oral, que "permite o registro de testemunhos e o acesso a "histórias dentro da história' e, dessa forma, amplia as possibilidades de interpretação do passado" (ALBERTI, 2006, p. 155). Neste artigo compreendo a história oral enquanto

[...] uma metodologia de pesquisa e de constituição de fontes para o estudo da história contemporânea surgida em meados do século XX [que] consiste na realização de entrevistas gravadas com indivíduos que participaram de, ou testemunharam, acontecimentos e conjunturas do passado e do presente (ALBERTI, 2006, p. 155).

Hoje as entrevistas produzidas a partir desta metodologia estão consolidadas entre os historiadores como fontes legítimas para a pesquisa histórica, embora ao longo do século XX se tenha discutido muito qual o grau de subjetividade envolveria a produção de tais fontes, já que as mesmas são o produto da memória dos entrevistados, mediada pelas interferências dos entrevistadores, ambos com anseios e interesses subjetivos. Para introduzir tal questão, parto da seguinte citação:

A conversa recaiu sobre uma última grande revolta das Highlands escocesas contra a dominação inglesa, a rebelião de 1745 . Johnson concordava que isso "daria uma bela peça histórica", mas discordava da dúvida de Elibank sobre "se alguém daquela época podia falar sobre ela imparcialmente", citando o método de Voltaire em seu Luís XIV: "Conversando com pessoas de lados diferentes, que tenham sido atores dela, [a rebelião escocesa contra a dominação inglesa] escrevendo tudo que ouvir, alguém poderá, antes que seja tarde, reunir o material para 
uma boa narrativa. Você deve considerar que, de início, toda a história era oral”. E nisso foi vigorosamente apoiado pelo historiador escocês, que também conhecia Voltaire: "É mais do que tempo, agora, de se fazer essa coleta sugerida pelo dr. Johnson; pois muitas das pessoas que, na ocasião, estavam em armas, estão desaparecendo" (THOMPSON, 1998, p. 55).

Independente de discutir-se aqui o quanto a historiografia tem se modificado de lá para cá, este diálogo ocorrido em 1773 traz elementos que ajudam a pensar o quanto é importante que os historiadores reúnam relatos orais que ajudem na construção do conhecimento histórico. A contribuição daqueles que foram 'atores' dos processos pode ser muito rica e não deve ser descartada. Se por muito tempo os historiadores deram créditos apenas às fontes escritas 'oficiais', e ao mesmo tempo primaram pelo estudo de tempos mais longínquos para evitar um possível envolvimento emocional 'subjetivo',

[...] essas convicções sobre o que seria próprio da História sofreram modificações a partir da década de 1980: temas contemporâneos foram incorporados à História, chegando-se a estabelecer um novo campo, que recebeu o nome de História do tempo presente; passou-se a valorizar também a análise qualitativa [para além das análises quantitativas e das fontes seriais], e o relato pessoal deixou de ser visto como exclusivo de seu autor, tornando-se capaz de transmitir uma experiência coletiva, uma visão de mundo tornada possível em determinada configuração histórica e social. (ALBERTI, 2006, p. 163).

Neste sentido, as entrevistas analisadas neste artigo devem ser encaradas como fontes históricas produzidas nos marcos da história oral, compreendendo esta última não apenas como "a técnica ou o conjunto de técnicas utilizadas para se extrair de alguém alguma informação de caráter histórico" (CORRÊA, 1978, p. 24), mas como uma metodologia que nos permite apreender uma série de informações e relações estabelecidas nas diversas esferas da sociedade que não poderiam ser alcançadas através da legislação ou de outras produçôes oficiais. Como aponta Verena Alberti, desta forma a História oral pode contribuir para transformar as produções históricas a respeito de temáticas políticas, afastando-as da velha 
“História dos 'grandes homens' e 'grandes feitos', e [colocando-as] sim como estudo das diferentes formas de articulação de atores e grupos de interesse” (ALBERTI, 2006, p. 166).

Neste artigo analiso oito entrevistas que fiz com professores que lecionaram em diferentes níveis do ensino e em diferentes disciplinas. ${ }^{3}$ Os relatos foram coletados sem a preocupação de recolher informações para uma avaliação quantitativa que priorizasse levantar, por exemplo, o número de vezes que aparecem durante as entrevistas as expressões "Acordos MEC-USAID" ou "COLTED" para verificar o quanto tais políticas eram conhecidas dos professores. $\mathrm{Na}$ verdade cada professor foi consultado para que pudesse dar o seu relato específico, a partir de suas vivências. Tais documentos não foram produzidos para confirmar ou negar aquilo que o Estado vinha documentando através da legislação, mas sim para enriquecer o estudo a respeito deste período, e para que fosse possível ampliar a análise a respeito das políticas educacionais para o livro didático a partir dos próprios relatos, conforme apresentados por seus protagonistas.

Para organizar a coleta de informações optou-se pela criação de um roteiro ${ }^{4}$ que pudesse funcionar como um guia durante a entrevista. Em momento algum este roteiro foi utilizado de maneira rígida, como um questionário pronto que pudesse impossibilitar o diálogo com os entrevistados ou a inclusão das novas perspectivas de análise e informações apresentadas por eles. Compreende-se, desta maneira, que a "entrevista é o que melhor se adapta a uma proposta de análise mais qualitativa do que quantitativa. É um método pelo qual se procura obter informações através de um interrogatório direto, durante uma conversa. É, pois, em sentido globalizante, orientada para um objetivo definido" (CORRÊA, 1978, p. 23).

Cada uma das entrevistas trouxe elementos novos, ao mesmo tempo em que o conjunto delas serviu para confirmar uma série de

3 Para maiores informações a respeito destes educadores, como contexto de atuação profissional e disciplinas lecionadas, ver Anexo II - Relação de Professores Entrevistados.

4 Para mais informações ver Anexo I - Roteiro Básico para Entrevistas. 
outras questões. Entre os elementos recorrentes aos depoimentos, por exemplo, estão os relatos a respeito da relação entre professores e editoras de livros didáticos naquele período. Conforme se analisa a seguir, das oito falas, seis convergem apontando para um padrão de atuação entre as editoras: elas enviavam aos professores exemplares de livros, tanto para aqueles que lecionavam na rede pública quanto na rede particular, divulgando seus materiais como estratégia de marketing.

O professor Celses Português Soares (SOARES, 2009, gravação digital) relatou que não havia distribuição de material didático gratuitamente por parte do Estado, “desses como nós temos hoje", no período em que começou a lecionar (1964), mas que o governo tinha preocupação com esta questão e que em seguida, sem saber precisar o momento, "começaram as estatísticas dizendo que tinha gente com muito material”, especialmente em escolas particulares onde lecionou em que bastava que o professor fizesse a lista de materiais para que os pais comprassem todos os livros, ao mesmo tempo em que muitos não tinham acesso a livro algum. Ele chegou a dar aula em turmas de escolas públicas em que em uma mesma sala apenas alguns alunos tinham livros e ainda assim nem sempre o mesmo, dificultando o trabalho com o grupo. Relatou que muitas vezes os alunos precisavam ir até a biblioteca da escola para pesquisar em enciclopédias na tentativa de cumprir as tarefas de aula e que em geral as aulas eram baseadas no conteúdo ditado pelos professores a partir de um livro didático que estes traziam de casa que, em geral, eram ganhos das editoras.

A professora Jandaraí Oliveira (OLIVEIRA, 2009, gravação digital) comentou que recebia os exemplares de livros das editoras e que comumente ia até a sede das mesmas conhecer as últimas publicações e fazer encomendas de livros para revender aos alunos a preço de custo. Disse que muitas vezes chegou a dar livros aos alunos que não tinham condições de comprar. Chegou a elogiar os materiais comentando que provavelmente as editoras não deveriam poder publicá-los sem o crivo do Estado, já que eram de boa qualidade, mas comentou que a maioria das aquisiçôes 
de material para a escola, seja livros, projetor de slides ou outros eram angariadas através do Círculo de Pais e Mestres, já que, em geral, a escola não recebia recursos do Estado para estes fins.

A professora Carmen Dotto (DOTTO, 2009, gravação digital) confirmou tanto a utilização de livros nas aulas quanto o recebimento deles através das editoras, mas discordou em relação à qualidade. Disse que na escola particular em que começou a lecionar, em 1964, o corpo docente podia escolher o material que pretendia utilizar, indicando-o aos alunos para que comprassem, mas que dificilmente os livros eram de qualidade: "eram muito pobres, não davam espaço para a pesquisa e os alunos não questionavam". Comentou também que, ao ingressar na escola pública, o acesso aos materiais por parte dos alunos era bem mais escasso e que costumava abandoná-los, utilizando outros materiais produzidos por ela. Comentou ainda a "claríssima diferença" entre os livros antes e depois da imposição do Ato Institucional n. $5,{ }^{5} \mathrm{em}$ dezembro de 1968: para ela, após o AI-5 os livros começaram a ser nitidamente censurados, assim como houve um acirramento da censura nos espaços escolares. Carmen chegou a relatar que teve suas aulas observadas por um agente do Departamento de Ordem Política e Social (DOPS) e que percebeu a situação somente quando foi alertada por um de seus alunos: "eu levava livros, falava de Revolução Russa, falava de Marx, e um dia um deles me chamou no corredor e disse: 'professora, a senhora tem que mudar! A senhora tenha cuidado porque aquele aluno que assiste a sua aula, ele não é nosso colega. Ele foi colocado na lista [de chamadas]'. Fui observar e ele realmente era do DOPS”.

Esta experiência relatada por Carmen demonstra o quanto o sistema repressivo era articulado e estava pronto para agir sempre

5 O Ato Institucional $n^{\circ} 5$. entrou em vigor no dia 13 de dezembro de 1968. Deu plenos poderes aos golpistas que estavam à frente do governo brasileiro e é considerado o ápice do autoritarismo da ditadura civil-militar no Brasil. Entre as determinaçốes impostas pelo AI-5 estão: o fechamento do Congresso Nacional por tempo indeterminado, a suspensão dos direitos políticos de qualquer cidadão pelo período de 10 anos, a proibição de manifestações de caráter político e a censura prévia a jornais, revistas, e manifestações culturais em geral. 
que necessário, ainda que nem todos os professores tenham sentido sua inferência mais direta. Um dos comentários feito pela professora Jandaraí levanta esta questão: "na minha aula eu nunca vi ninguém. Eu acho que não houve interferência, assim. A gente é que tinha medo. Talvez, se eu fizesse alguma coisa que a diretora fosse denunciar, [agentes do Estado] viessem observar”. É ilustrativo perceber o quanto o recurso do medo - medo de ser observado; medo de fazer algo que pudesse ser denunciado, etc. - servia para garantir o controle sobre grande parte da população, diminuindo assim a necessidade de recorrer à aplicação efetiva de medidas violentas de controle social. Nem todos os professores precisaram ser observados, pois já mantinham uma postura regulada por esta "pedagogia" do medo e do terror.

Na sequência das entrevistas, a professora Vera Barroso (BARROSO, 2009, gravação digital), que lecionou a partir de 1969, também afirmou que ganhava livros das editoras. Sobre o processo de recebimento dos mesmos, acrescentou que em um primeiro momento vinha uma cota de livros gratuitos para a biblioteca - em torno de 40 ou 50 de cada disciplina e etapa do ensino - que os alunos usavam em aula e em seguida devolviam. Logo depois os livros passaram a ser escolhidos pela equipe docente das escolas a partir de listas de livros que o MEC oferecia em parceria com algumas editoras, mas Vera sublinhou que nem todos os livros estavam presentes neste universo de escolha. Comentou, inclusive, que desejava trabalhar com a coleção "do Chico Alencar, da [editora] Vozes, só que este não estava na lista”. Neste momento do relato, referindo-se ao livro didático como uma mercadoria, Vera evidencia sua compreensão de que a Ditadura Civil-militar e algumas editoras tinham "combinações" em relação ao conteúdo transmitido nos livros, fazendo com que nem todas as editoras fossem financiadas pelo governo.

Levando-se em consideração o período em a professora Vera Barroso começou a lecionar, ainda que ela não tenha precisado os programas ou políticas educacionais que determinavam as ações do Estado em relação aos livros didáticos, compreende-se 
que no primeiro momento ela está se referindo aos livros distribuídos a partir da COLTED com o financiamento dos acordos MEC-USAID, e no segundo momento, aos livros distribuídos pelo INL a partir de seu programa de coedições, conforme analisando anteriormente.

O professor Valmir Giacominni (GIACOMINNI, 2009, gravação digital), que começou a lecionar em 1970 a partir do curso normal e até 1973 trabalhou apenas com as séries iniciais do curso primário, lembrou-se de haver livros didáticos para as disciplinas de português e estudos sociais, mas não para as demais. Lecionando na rede particular durante estes anos, também relatou que os livros eram escolhidos pela coordenação da escola e comprados pelos pais dos alunos, mas não se lembrava de participar, enquanto professor, da escolha dos materiais. Comentou com ênfase as visitas feitas às escolas particulares pelos chamados divulgadores que, representando as editoras, apresentavam seus materiais aos professores e coordenadores para convencê-los a adotá-los. Logo que entrou na rede pública sentiu que a "situação era bem pior", pois a grande maioria dos alunos não podia comprar os livros, mas ressalta a existência de boas bibliotecas nestas escolas. As bibliotecas podiam ser consultadas pelos alunos, ainda que eles precisassem solicitar o título desejado à bibliotecária, sem ultrapassar um balcão. Para Valmir, este procedimento também era uma forma de controlar o que os alunos liam. É interessante lembrar que o INL tinha como uma de suas funções, desde sua criação em 1937, promover e subsidiar a formação de bibliotecas em todo o país, provavelmente motivo pelo qual mais de um professor citou a existência das mesmas dentro das escolas.

A professora Maria Aparecida Morange (MORANGE, 2009, gravação digital), que entrou para o magistério em 1970, lembrou que alguns anos depois de ter começado a dar aulas, em torno de 1975, tanto ela quanto seus alunos passaram a receber livros do Estado gratuitamente, mas não se lembrou de ter notícias através de qualquer tipo de informativo ou propaganda a respeito de qualquer política para esta área. Também não se lembrou de maiores detalhes 
a respeito de como obtinha os livros que usava para preparar suas aulas antes disto. Mencionou, assim como outros professores, que nocomeço de sua atuação usava-se muito o mimeógrafo para preparar as lições que seriam transmitidas aos alunos.

À exceção das entrevistas citadas até aqui, a professora Elohá Orokoski Machado (MACHADO, 2009, gravação digital), que começou a lecionar Biologia em 1968, não se lembrava de utilizar ou receber livros didáticos de nenhuma editora. Ela diz que em sua disciplina os professores ministravam o que estava no programa de acordo com os materiais que desejassem. Quando questionada sobre sentir ou não algum tipo de interferência em sala de aula por parte da Ditadura Civil-militar, Elohá comentou que naquele período "os professores de história é que estavam mais engajados nesse tipo de coisas [militância política]. A gente que estava na área científica não estava 'nem aí'. Politicamente na época não éramos muito engajados”. Provavelmente seu relato expressa uma percepção diferente da realidade justamente por sua atuação ter se dado em uma disciplina 'científica' e não ligada às ciências humanas, mas também porque a disciplina de biologia era ministrada apenas no chamado $2^{\circ}$ Grau, nível de ensino pouco difundido no Brasil naquele período, quando nem mesmo o ensino fundamental, ou $1^{\circ}$ Grau, era universalizado. Assim, os programas instituídos para executar as políticas do livro didático, em geral, eram focados no $1^{\circ}$ Grau.

Já a professora Guacira Gigante (GIGANTE, 2009, gravação digital), que começou a lecionar Educação Artística em 1971, fez um relato diferenciado dos demais justamente por ter ingressado no magistério em um dos Ginásios Polivalentes implantados a partir do desenvolvimento de um dos projetos prioritários previstos no Planejamento Setorial da Educação para os anos entre 1970 e $1973 .{ }^{6}$ O projeto previa a construção e equipamento de 257 ginásios polivalentes apenas no estado do Rio Grande do Sul,

6 Sobre este projeto ver: BRASIL. MEC. Secretaria Geral. Planejamento Setorial: projetos prioritários 1970/1973. [Brasília]: MEC, [1969?], p. 27-30. 
além de treinamento para diversos professores. Foram feitas provas seletivas para participação nos cursos preparatórios, que tinham caráter eliminatório e classificatório. A atuação se dava em instituições tecnicistas de caráter experimental que pretendiam substituir o ensino teórico e acadêmico dos antigos ginásios pelo ensino profissionalizante. Conforme afirmou Guacira, os ginásios polivalentes começaram a funcionar em 1970 e já estavam totalmente desarticulados em 1976. Ainda assim, durante os anos em que o projeto vigorou principalmente através de recursos dos Acordos MEC-USAID, os Ginásios possuíam total infraestrutura, desde equipamentos até salas de aula e materiais didáticos. Neste caso, não faltava livros para nenhum aluno. É importante ressaltar que, de acordo com o relato, todos os materiais eram distribuídos pelo Estado, sem participação dos professores na escolha. Ainda assim, Guacira ganhava livros das editoras, mas disse que sentia resistência por parte da coordenação da escola quando tentava levar ou indicar outros materiais que the pareciam de qualidade superior.

Excetuando-se as duas últimas entrevistas citadas, em todas as seis mencionadas anteriormente houve referências ao recebimento de livros didáticos diretamente das editoras como a principal forma de aquisição de livros pelos professores no período entre 1964 e 1974. Célia Cassiano traz um relato a respeito da constituição desta prática por parte das editoras:

Um episódio referente à Editora Ática (HISTÓRIA..., 2001) aparentemente ilustra o início da presença dos divulgadores nas escolas. Um dos donos dessa editora era o doutor Anderson Fernandes Dias, que, como médico, recebia inúmeras visitas de representantes de laboratórios que lhe doavam amostras grátis dos medicamentos. Viu, nessa experiência, uma solução para enfrentar os desafios que a editora vivia nos seus primeiros anos de existência. Por analogia, criou uma pequena equipe de vendas, que passaria a visitar diretamente o professor para doar, e não vender, livros didáticos. Tais práticas seriam incorporadas por todas as grandes editoras de didáticos do País, agora não com pequenas equipes, mas com grandes equipes especializadas. (CASSIANO, 2005, p. 301). 
Levando-se em consideração que a Editora Ática foi fundada em 1965, percebe-se que a idéia de se fazer propaganda dos materiais produzidos pelas editoras a partir da entrega de 'amostras grátis' aos professores surgiu paralelamente ao crescimento da concorrência no setor, por sua vez, impulsionada pelo incentivo estatal à área. Após o golpe, estimuladas principalmente pelas novas políticas educacionais e em seguida respondendo ao crescimento da demanda do ensino a partir da obrigatoriedade de oito anos de escolaridade estabelecida pela Lei de Diretrizes e Bases da Educação Nacional de 1971, as editoras passaram a refinar suas estratégias de marketing. Além de distribuir livros gratuitamente, ainda passaram a utilizar-se da "distribuição de folders promocionais, [de] um corpo de assessoria composto por professores universitários, além de palestras com os próprios autores" (CASSIANO, 2005, p. 307). Com o crescimento da concorrência, que levou a uma necessidade cada vez maior de modernização e qualificação gráfica dos materiais, os livros didáticos foram se tornando cada vez mais caros. A partir da parceria financeira entre Estado e empresas foi se constituindo um núcleo cada vez mais delimitado de editoras capazes de seguir na disputa por esta área do mercado editorial no país.

A análise da legislação, dos projetos oficiais que instituíram as políticas para o livro didático e das entrevistas aponta para a constatação de que o modelo de desenvolvimento econômico aplicado pelos militares à economia nacional a partir de 1964 foi estendido também à política do livro didático. Além de centralizar na União as decisões em relação à política educacional do livro, possibilitando ao Estado um maior controle daquilo que seria produzido e das idéias que seriam disseminadas nas escolas através dos materiais, a ditadura civil-militar ainda priorizou a aliança com o capital internacional e com o empresariado local subsidiando "o desenvolvimento industrial do respectivo setor, incentivando a formação de poucos grupos empresariais que exploravam e detinham a produção do setor” (SERPA, 1987, p. 16), em detrimento de políticas que priorizassem a qualificação dos 
educadores ou parcerias com os sistemas estaduais e municipais de ensino na tentativa de incentivar a produção local de materiais e recursos didáticos.

A observação de livros didáticos publicados no período também contribui para explicitar tais questões. Entre os livros analisados, aquele que possui publicação mais antiga (IRMÃOS MARISTAS, 1966) é um livro pequeno (em formato 14 X $18 \mathrm{~cm}$ ), sem gravuras, bastante cronológico e factual. O texto está organizado de acordo com a sucessão dos presidentes da república, com os principais fatos ocorridos em cada governo. Naquele ano o manual já estava na $25^{\text {a }}$ edição e o texto atualizado recentemente, já que apenas dois anos após o golpe militar já constava um parágrafo, ao final do livro, com referências aos acontecimentos de 1964. Ainda que seja um texto curto, apresenta um posicionamento bastante claro, apresentando a intervenção dos militares como a salvação para a nação brasileira, que estaria sobre forte ameaça comunista:

Outro exemplar, com publicação de 1970 (CASTRO, 1970) já apresenta muitas inovações estéticas. Apresenta-se em formato 21 X $28 \mathrm{~cm}$, é bastante colorido e atrativo, organizado como se fosse uma história em quadrinhos. Mas o texto ainda é bastante simplista e segue sendo organizado com base nas sucessões de presidentes e fatos políticos, de maneira cronológica e factual. A simplificação deixa várias lacunas, por exemplo: em um dos quadrinhos, que comenta a realização do plebiscito ocorrido durante o governo João Goulart para que a população optasse entre o sistema de governo parlamentarista e o presidencialista, o texto diz: "Durante o governo do último [João Goulart] foi realizado um plebiscito que determinou a volta do país ao presidencialismo. Merece destaque, no campo da política externa do governo João Goulart, sua visita ao México, onde foi recebido com grandes manifestações” (CASTRO, 1970, p. 164). Na sequência, sem maiores explicações, passa-se a falar da deposição de Goulart e da implantação do novo governo: 
Após um período de grande agitação política e social, em que pontificavam vários extremistas, com o aumento da inflação e as dificuldades crescentes das condições de vida no país, João Goulart é deposto no dia 31 de março de 1964, por um movimento que, começado em Minas Gerais, rapidamente se espalhou pelo país [...] O poder é entregue outra vez a Ranieri Mazzilli. Os chefes da Revolução baixam o Ato Institucional, modificando a constituição. Suprimem-se as garantias individuais para permitir a cassação de mandatos e direitos políticos. O movimento se declara contra a corrupção e a subversão (CASTRO, 1970, p. 165).

Observa-se o golpe sendo colocado como "Revolução", além da justificação para a supressão das garantias individuais pela existência de "corrupção e subversão". O livro continua relatando até o governo Garrastazu Médici, mas passa de maneira superficial sobre os atos institucionais, sem comentar repressão ou tortura. Ao comentar o AI-5, por exemplo, logo abaixo é justificado pelo crescente "terrorismo", citando como exemplo o seqüestro do embaixador norte-americano Charles Elbrick. Entre o golpe e o governo Médici, o texto dá atenção às medidas econômicas da ditadura, como a criação do Cruzeiro Novo para controlar a inflação; a construção de estradas, em especial na Amazônia; e a expansão das telecomunicações. Percebe-se a exaltação da nação e de seu crescimento, proporcionado pela ação das Forças Armadas com base na doutrina de segurança nacional.

Já um exemplar de 1979, da disciplina de OSPB (PILETTI, 1979), embora esteja fora do marco temporal central deste trabalho, ajuda a ilustrar o quanto evoluiu graficamente o processo de produção e diagramação dos livros em relação àqueles publicados logo depois do golpe. É um material cheio de imagens coloridas, com recursos didáticos como a utilização de esquemas e quadros comparativos, mas preserva a ausência de problematizações em relação à organização do Estado e do governo no Brasil, frisando, por outro lado, as ações, programas e metas de desenvolvimento. No capítulo intitulado "Como é governado o Brasil?” (PILETTI, 1979, p. 84-91) o país é definido como uma República Federativa governada nos marcos da democracia representativa. Em nenhum momento são questionados, por exemplo, os mecanismos e manobras 
utilizados pela ditadura, chamada no livro de "poder revolucionário", para garantir plenos poderes ao executivo, mesmo que uma das características fundamentais da República fosse a divisão nos três poderes.

Em geral, entre os livros observados, os primeiros possuíam uma qualidade técnica inferior, eram publicados em tamanho menor, não traziam propostas de exercícios e eram pouco ilustrados, enquanto os livros produzidos principalmente a partir de 1970 passaram a apresentar nítidas modificações. A professora Vera Barroso relatou ter percebido estas alterações, principalmente ao comparar os livros didáticos que utilizava enquanto estudante, em torno da década de 1950, e aqueles que passaram a ser disponibilizados pelo Estado durante o regime militar. Os primeiros eram "livros de muita descrição, poucas imagens, preto e branco em suas ilustrações e uma história narrativa de grandes fatos, grandes homens". Já os demais se modificaram principalmente "do ponto de vista formal, com mais ilustrações, e eram mais enxutos os textos. Bem mais curtos".

Estas mudanças observadas, tanto diretamente através dos livros quanto a partir das entrevistas, demonstram que o aumento da concorrência incentivava a qualificação formal dos livros didáticos, ao mesmo tempo em que o ensino voltado para a formação de mão-de-obra qualificada para o mercado de trabalho brasileiro passava a priorizar cada vez menos a densidade ou a profundidade de informações, principalmente nas áreas humanas, em prol de um ensino objetivo, rápido e "produtivo", deixando de lado as discussões que pudessem dar aos educandos uma compreensão mais dinâmica e completa da estrutura social, política e econômica na qual estavam inseridos.

Além dos elementos apontados até aqui, a análise das entrevistas também evidencia entre os professores diferentes posições em relação ao tratamento dado pela ditadura à educação. Para o professor Celses, que comentou nunca ter se posicionado em sala de aula a favor ou contra a ditadura civil-militar, os objetivos que o governo tinha ao desenvolver suas políticas educacionais 
giravam em torno de "desenvolver o sentimento patriótico", que incluía o respeito pela pátria e pelos outros. Para ele, aqueles que eram contra a ditadura acreditavam que "tudo o que o governo fez foi para manipular a mente das pessoas”, mas a sua opinião, enquanto professor que atuou no período, é que o principal interesse, principalmente ao instituírem-se disciplinas como Educação Moral e Cívica, e a OSPB, era o de criar "uma mentalidade honesta, responsável, consciente” que pudesse ajudar os cidadãos a refletir sobre as diferentes situações que poderiam "prejudicar o país". Para ele, não havia problemas em discutir diversos temas com os alunos em sala de aula e em nenhum momento chegou a comentar sobre sentir medo ou sentir-se reprimido. Apenas acrescenta que "talvez a crítica que caiba ela [a política educacional] foi implantada assim, de cima para baixo".

Diferindo da opinião do professor Celses, a professora Vera comentou que era um período de exceção em que o governo tentava controlar o ensino. Para confirmar sua posição chegou a relatar um episódio em que uma coleção de livros, que trazia liçôes de gramática e leitura a partir de textos que falavam de problemas sociais como o casebre, a favela, etc., foi denunciada e apreendida pelo Estado por ser "movimentadora de cabeças". Para ela, a coleção apresentava bons livros que foram proibidos não por sua qualidade, mas justamente por denunciarem a existência de problemas sociais no Brasil, ao invés defender o crescimento econômico da nação através de uma perspectiva ufanista.

A respeito do patriotismo ufanista difundido no período através da educação, este também foi um tema recorrente nas entrevistas. Excetuando-se o relato do professor Celses, que via no patriotismo um elemento importante para a formação dos cidadãos brasileiros no período e da professora Elohá, que não comentou esta questão, todos os demais entrevistados comentaram os excessos em relação à defesa da nação brasileira, de seus símbolos e de seus governantes. $\mathrm{O}$ respeito à bandeira, $\mathrm{O}$ conhecimento do Hino Nacional e dos nomes de governantes eram pontos obrigatórios dos currículos, tanto para aqueles que 
lecionavam História quanto para aqueles que trabalhavam com Moral e Cívica ou OSPB. Até mesmo o professor Valmir, que trabalhou com alfabetização e mais tarde com língua portuguesa, comentou que em todos os materiais havia elementos que estimulavam o patriotismo, como as cores da bandeira ou os símbolos nacionais. Relatou ainda que grande parte dos textos traziam temáticas que enalteciam o Brasil, suas belezas e seu crescimento. $\mathrm{O}$ livro Português Moderno, da F.D.T., por exemplo, trazia como suple-mento a letra e as partituras de todos os "hinos patrióticos" (GIACOMOZZI, 1966, p. 141-147) como o Hino Nacional, o da Bandeira, o da Independência e ainda a Canção do Soldado. Ainda pode-se ressaltar a presença de textos exaltando os valores defendidos pelo Estado que faziam parte da estratégia psicossocial de convencimento da população, como o amor à família, que era considerada o núcleo fundamental da sociedade (GIACOMOZZI, 1966, p. 34-35).

Para a professora Maria Aparecida havia um ufanismo excessivo que escamoteava certas discussões enquanto se enaltecia os grandes feitos do desenvolvimento econômico do país. Mesmo a professora Jandaraí, que via com simpatia o respeito que se tinha pelo Brasil naquela época, comentou que os próprios currículos já vinham desenhados de maneira a fazer com que os professores trabalhassem o patriotismo, citando a obrigatoriedade de que todos se envolvessem na organização dos eventos da Semana da Pátria.

A riqueza das informações que foram transmitidas pelos entrevistados deixa evidente o quanto as experiências e percepções que cada um têm hoje em relação àquele período estão intimamente relacionadas com o contexto imediato no qual estavam inseridos, com seu posicionamento político-ideológico e com sua forma de atuar social e profissionalmente. Além disto, as entrevistas ajudam a perceber as diferentes maneiras possíveis de se relacionar com as políticas educacionais construídas pelo Estado: enquanto alguns professores criticavam os livros didáticos e esforçavam-se para utilizar materiais diversificados, outros, conforme relata a professora Vera Barroso, chegavam a idolatrá-los, transformando-os em "uma 
bengala para que não precisassem 'se matar' preparando aula. O sumário do livro acabava virando o programa de trabalho". Desta maneira, percebe-se que o livro didático passou a cumprir um papel fundamental em sala de aula, principalmente em meio ao crescimento da demanda social por educação vivenciado nas décadas de 1960 e 1970.

Em um país que preteria a qualificação pedagógica e crítica dos professores em favor de resolver os problemas da educação a partir de medidas paliativas e assistencialistas, não é de se surpreender que os livros didáticos fizessem tanto sucesso entre boa parte dos educadores. Mas por outro lado, as entrevistas ajudam a enxergar além da informação oficial, permitindo que se percebam outras perspectivas de análise que mediam a ação dos indivíduos com o controle do Estado. Mesmo em meio à censura e à repressão havia brechas para a atuação mais livre dos educadores, permitida inclusive pela dificuldade que o próprio Estado tinha de aplicar efetivamente todas as suas políticas e todos os seus mecanismos de controle em cada canto do país. Assim, muitos professores conseguiam levar discussões diversas para dentro de suas salas de aula, tentando fazer certas críticas, ainda que precisassem ser veladas, como afirmou a professora Jandaraí. Isto não significa relativizar o uso da violência ou a aplicação das estratégias psicossociais como mecanismo de coerção por parte da ditadura civilmilitar, mas apenas admitir a ação dos sujeitos e valorizar suas formas de resistir e compreender a realidade.

É certo que em 1964 já existiam livros didáticos, mas é certo também que neste período pouquíssimos alunos tinham acesso a eles, excetuando-se basicamente aqueles que tinha poder aquisitivo suficiente para comprá-los. Mas, ao longo dos 10 anos enfocados nesta análise, o livro didático passou a ter um alcance muito maior, tanto para professores quanto para alunos. Em geral os entrevistados registraram que durante a década de 1970 tais materiais começaram a circular mais nas escolas, mencionando primeiro a venda a preço de custo e, mais a diante, os primeiros exemplares oferecidos de maneira gratuita, principalmente para os 
alunos 'carentes', ajudando a caracterizar a política do livro didático como uma política assistencialista.

Pode-se afirmar também que os mecanismos de censura impostos pelo Estado ao livro didático durante o período ditatorial brasileiro acabaram centrando-se ainda no processo de produção, minimizando a necessidade de utilizar sanções legais para censurar e impedir a comercialização ou reprodução de determinados pontos de vista, a partir do momento em que as próprias editoras passaram a ligar-se ao Estado através de acordos econômicos que poderiam proporcionar lucros a essas.

Obviamente, não podemos comparar o alcance dos programas desenvolvidos pela COLTED ou pelo INL durante as décadas de 1960 e 1970 com os que são desenvolvidos hoje pelo FNDE, que entrega livros gratuitamente para todos os alunos da rede pública de ensino através do Plano Nacional do Livro Didático (PNLD), mas com certeza a centralidade do livro didático no processo de ensino e aprendizagem e as bases para estas políticas educacionais foram lançadas durante a primeira metade da ditadura civil-militar brasileira.

\section{Referências}

ALBERTI, Verena. Fontes Orais: Histórias dentro da História. In: PINSKY, Carla. Fontes Históricas. 2 ed. São Paulo: Contexto, 2006.

ALTHUSSER, Louis. Ideologia e Aparelhos Ideológicos do Estado. 3. ed. Lisboa: Editorial Presença, 1980.

BRASIL. MEC. Secretaria Geral. Planejamento Setorial: projetos prioritários 1970/1973. [Brasília]: MEC, p. 27-30, 1969.

BRAZ, Maria; OLIVEIRA, Cândido. Vamos Sorrir. I Livro de Leitura. v. 1. São Paulo: F.T.D., 1968. (Livro Didático)

. Vamos Sorriv. II Livro de Leitura. v. 2. São Paulo: F.T.D., 1965. (Livro Didático) 
BRAZ, Maria. Vamos Sorriv: III Ano Primário. v. 3. São Paulo: F.T.D., 1966. CARVALHO, L.G. Motta. Ensino moderno de história do Brasil. São Paulo: Editora do Brasil, [197-?].

CASSIANO, Célia Cristina de Figueiredo. Reconfiguração do mercado editorial brasileiro de livros didáticos no início do século XXI: história das principais editoras e suas práticas comerciais. Em Questão, Porto Alegre, v. 11, n. 2, p. 281-312, jul./dez. 2005.

CASTRO, Julierme de Abreu e. História do Brasil. v. 2. São Paulo: IBEP, 1970.

CORREAA, Carlos Humberto P. História Oral: teoria e técnica. Florianópolis: UFSC, 1978.

CURY, Carlos Roberto Jamil. Livro Didático como Assistência ao Estudante. In: Revista Diálogo Educacional, Curitiba, v. 9, n. 26, p. 119-130, jan./abr. 2009.

FREITAG, Bárbara; MOTTA, Valéria Rodrigues; COSTA, Wanderley Ferreira. O Estado da Arte do Livro Didático no Brasil. Brasília: INEP, 1987.

GATTI Jr., Décio. A escrita escolar da História: livro didático e ensino no Brasil (1970-1990). São Paulo: Edusc; Uberlândia: Edufu, 2004.

GERMANO, José Willington. Estado militar e educação no Brasil (19641985). São Paulo: Cortez, 1993.

GIACOMOZZI, Gilio. Português Moderno. São Paulo: F.T.D., 1966. (Livro Didático)

IRMÃOS MARISTAS. História do Brasil: 4. e. 5. Ano Primário e Admissão ao Ginásio. 25 ed. São Paulo: F.T.D., 1966. (Livro Didático)

OLIVEIRA, João Batista Araújo; GUIMARÃES, Sonia Dantas Pinto; BOMÉNY, Helena Maria Bousquet. A Política do Livro Didático. São Paulo: Summus; Campinas: Ed. da UNICAMP, 1984.

PILETTI, Claudino. OSPB, Organização Social e Politica Brasileira: $1^{\circ}$ grau. 6 ed. reformulada e ampliada. São Paulo: Ática, 1979.

PORTELLI, Hugues. Gramsci e o bloco histórico. Rio de Janeiro: Paz e Terra, 1977. 
ROMANELLI, Otaíza de Oliveira. História da Educação no Brasil (1930-1973). 7 ed. Petrópolis: Vozes, 1985.

SERPA, Luiz Felipe. A questão do livro didático. In: INEP, Em aberto, Brasília, ano 6, n. 35, jun./set. 1987.

THOMPSON, Paul. A voz do passado: história oral. 2 ed. Rio de Janeiro: Paz e Terra, 1998.

\section{Fontes consultadas}

\section{Entrevistas}

BARROSO, Vera. Entrevista: professora Vera Barroso. Entrevista concedida a Clarissa de Lourdes Sommer Alves. Porto Alegre, 04 de novembro de 2009. Duração de $24 \mathrm{~min} 30 \mathrm{seg}$. Gravação digital em formato WAV.

DOTTO, Carmen. Entrevista: professora Carmen Dotto. Entrevista concedida a Clarissa de Lourdes Sommer Alves. Porto Alegre, 14 de outubro de 2009. Duração de 23minl8seg. Gravação digital em formato WAV.

GIACOMINNI, Valmir. Entrevista: professor Valmir Giacominni. Entrevista concedida a Clarissa de Lourdes Sommer Alves. Porto Alegre, 18 de novembro de 2009. Duração de 21 min $15 s e g$. Gravação digital em formato WAV.

GIGANTE, Guacira. Entrevista: professora Guacira Gigante. Entrevista concedida a Clarissa de Lourdes Sommer Alves. Porto Alegre, 14 de outubro de 2009. Duração de $31 \mathrm{~min} 08 \mathrm{seg}$. Gravação digital em formato WAV.

MACHADO. Elohá Orokoski. Entrevista: professora Elohá Orokoski Machado. Entrevista concedida a Clarissa de Lourdes Sommer Alves. Porto Alegre, 15 de outubro de 2009. Duração de 26min09seg. Gravação digital em formato WAV.

MORANGE, Maria Aparecida. Entrevista: professora Maria Aparecida Morange. Entrevista concedida a Clarissa de Lourdes Sommer Alves. 
Porto Alegre, 20 de novembro de 2009. Duração de 18minl9seg. Gravação digital em formato WAV.

OLIVEIRA, Jandaraí. Entrevista: professora Jandaraí Oliveira. Entrevista concedida a Clarissa de Lourdes Sommer Alves. Porto Alegre, 14 de outubro de 2009. Duração de 40min50seg. Gravação digital em formato WAV.

SOARES, Celses Português. Entrevista: professor Celses Português Soares. Entrevista concedida a Clarissa de Lourdes Sommer Alves. Porto Alegre, 06 de outubro de 2009. Duração de 50min20seg. Arquivo em formato WAV.

\section{Leis e Decretos}

Decreto-Lei n ${ }^{\circ} .93$, de 21 de dezembro de 1937.

Decreto-Lei no ${ }^{\circ}$ 1.006, de 30 de dezembro de 1938.

Decreto-Lei n ${ }^{\circ}$.6.339, de 11 de março de 1944 .

Decreto-Lei $n^{\circ} .8 .460$, de 26 de dezembro de 1945 .

Decreto-Lei $n^{\circ} .38 .556$, de 12 de janeiro de 1956.

Decreto $\mathrm{n}^{\circ} .50 .489$, de 25 de abril de 1961 .

Decreto $\mathrm{n}^{\circ}$. 53. 583, de 21 de fevereiro de 1964.

Decreto $\mathrm{n}^{\circ} .53 .887$, de 14 de abril de 1964 .

Decreto $\mathrm{n}^{\mathrm{O}} .58 .653$, de 16 de junho de 1966.

Decreto $n^{\circ} .59 .355$, de 04 de outubro de 1966.

Decreto $n^{\circ} .68 .728$, de 09 de junho de 1971.

\section{Anexos}

\section{Roteiro Básico para Entrevistas}

1. Qual o teu nome?

2. Em que ano começaste a lecionar?

3. Em qual instituição de ensino?

4. Em qual área de atuação/disciplina?

5. Como se deu a tua formação? Em que instituições de ensino?

6. Tens alguma lembrança relativa aos materiais didáticos que eram utilizados em sala de aula no seu período de estudante? 
7. Poderias comentar um pouco a respeito da escolha da tua profissão?

8. E no período em que começaste a lecionar? Qual a lembrança que tens em relação aos materiais didáticos que utilizavas em aula, ou que eram oferecidos pela escola?

9. O Estado fornecia de alguma forma informações a respeito das publicações didáticas oferecidas no mercado?

10. Lembra-te se havia alguma relação entre professores, equipes pedagógicas das escolas e as editoras de livros didáticos, como visitas de equipes das editoras às escolas, reuniões de apresentação de materiais, ou para qualquer proposta de trabalho conjunto? 11. Hoje existem programas como o PNLD e o PNLEM, que visam abastecer a rede pública de ensino com materiais didáticos. Em geral estes planos contam com a participação dos professores na escolha dos materiais, de acordo com certo universo de livros. Tens lembranças a respeito de algum programa governamental nesta área quando começaste a lecionar?

12. Se tens, lembra-te se havia a participação dos educadores no processo de construção, publicação, escolha e distribuição dos livros? 13. Tens outras lembranças referentes a este período (19641974) que consideres importante acrescentar para uma melhor compreensão do sistema de ensino à época?

\section{Relação de Professores Entrevistados}

Entrevista 1: Celses Português Soares.

Área de atuação: Religião, Filosofia, OSPB, Educação Moral e Cívica e Estudos de Problemas Brasileiros.

Ano de ingresso no magistério: 1964.

Contextos de atuação profissional: começou lecionando Ensino Religioso em Cruz Alta/RS para alunas do Curso Normal de uma escola pública (não lembrou o nome da instituição). Entre 1966 e 1967 dirigiu um orfanato em Santa Maria/RS. Em 1968 veio para Porto Alegre, começando a lecionar no IPA. Em 1970 vai trabalhar, ao mesmo tempo, na escola pública, primeiro no Colégio Padre Rambo, e em seguida no Colégio Santos Dumont, 
ambos em Porto Alegre. Na mesma época passou a lecionar Estudos de Problemas Brasileiros na UFRGS.

Entrevista 2: Guacira Gigante.

Área de atuação: Educação Artística. Lecionou apenas na rede pública. Ano de ingresso no magistério: Agosto de 1971.

Contextos de atuação profissional: Começou lecionando no Ginásio Polivalente do Bairro Canudos, na cidade de Novo Hamburgo/RS. Lecionou também na Escola Nações Unidas, no Bairro Nonoais, em Porto Alegre.

Entrevista 3: Carmen Dotto.

Área de atuação: História e OSPB.

Ano de ingresso no magistério: 1964.

Contextos de atuação profissional: Iniciou sua atuação no Colégio Rui Barbosa, escola particular laica que se situava na Avenida Osvaldo Aranha, em Porto Alegre. Assumiu cargo no Estado em 1967, conciliando o trabalho em escolas com horas na Secretaria de Educação.

Entrevista 4: Jandaraí Oliveira.

Área de atuação: Alfabetização, História e Moral e Cívica. Ano de ingresso no magistério: 1957.

Contexto de atuação profissional: Começou a lecionar em escola pública da cidade de Panambi/RS, sendo mais tarde transferida para a Escola Normal Annes Dias, em Cruz Alta, onde havia estudado muitos anos. Veio para Porto Alegre entre 1964 e 1965, transferida para a Escola de Primeiro Grau Ceará, onde começou lecionando para turmas em processo de alfabetização. Em seguida passou a lecionar História e Moral e Cívica. Chegou a lecionar também na cidade de Tapes, na escola em que seu marido era diretor, agregando mais 12 horas à já trabalhadas em Porto Alegre.

Entrevista 5: Elohá Orokoski Machado.

Área de atuação: Biologia.

Ano de ingresso no magistério: 1968. 
Contexto de atuação profissional: Começou a lecionar na Escola Glicério Alves, no Bairro Belém Velho em Porto Alegre. Depois de um ano conseguiu transferência para a Escola Infante Dom Henrique, no bairro Menino Deus.

Entrevista 6: Vera Lúcia Maciel Barroso.

Área de atuação: Lecionou apenas Música de 1973. A partir então começou a lecionar História, Geografia, Religião, OSPB e Educação Moral e Cívica.

Ano de ingresso no magistério: Setembro de 1969.

Contexto de atuação profissional: Começou a atuar no Ginásio Estadual de Santo Antônio da Patrulha/RS, onde ficou até 1974. Neste ano pediu transferência para a cidade de Cachoeirinha, atuando na Escola Presidente Kenned, que era um dos Ginásios Polivalentes implantados no período, local onde permaneceu dando aulas até 1985. Em 1975 agregou mais 20 horas no Ginásio Polivalente de Alvorada, que hoje é a Escola Érico Veríssimo.

Entrevista 7: Valmir Giacominni.

Área de atuação: Alfabetização, Letras - Português e Literatura. Ano de ingresso no magistério: 1970.

Contexto de atuação profissional: Começou a lecionar no Colégio das Dores de Porto Alegre, onde permaneceu por 13 anos. Até 1973 lecionou somente para as séries primárias. A partir de então passou a lecionar também Português para as séries finais do então "10 Grau". Até 1976 lecionou apenas na rede privada, ano em que ingressou na rede pública no Colégio Pio XII, onde lecionou para o Ensino Médio também Literatura.

Entrevista 8: Maria Aparecida Morange.

Área de atuação: Alfabetização e Supervisão Escolar.

Ano de ingresso no magistério: 1970.

Contexto de atuação profissional: Iniciou no Grupo Escolar Rubem Berta, no Bairro Cavalhada, em Porto Alegre. Em seguida foi transferida para o Grupo Escolar Paula Soares, no Centro de Porto Alegre. Lecionou apenas na rede pública. 